\title{
Conquering the New Challenges Faced
}

It is always a pleasure to announce the publication of a new issue of Acta Baltica Historiae et Philosophiae Scientiarum. We have reasons to believe that we have successfully started conquering the new challenges mentioned in the editorial of the last issue. The achievements we are building on have become more solid than ever before. The journal has acquired a truly global reach. Further explanation follows.

The current issue includes a strong Asian component concerning both content and contributors. The paper by Per Högselius and Yao Dazhi discusses a relatively typical and thoroughly studied phenomenon of technology transfer in a somewhat unconventional way. Normally, scholarly papers just analyse technology transfer from the West to the East. Högselius and Dazhi seek a more balanced approach, expressing their views in an elaborate theoretical and terminological framework. Another paper also links together the West and the East. Logic has obtained the status of an ideally neutral discipline, both in the psychological and the cultural sense. However, in the reality of dealing with logic, culture still shines through. Therefore, it is especially interesting to analyse Eastern contributions to traditional topics in logic. Late Jin Yuelin has done this in a masterful way. Our journal has the honour of being the first to publish the English translation of Yuelin's influential paper. The second part of the paper will appear in the next issue of Acta Baltica. The third main contribution to the current issue proves that mathematics could be taken as a recreational activity already a couple of centuries ago. Mathematics can be fun not just for mathematicians. However, it is never just that but always provides those involved with the means to develop their mental capacities and enhance communication and social belonging. One paper in the current issue falls under the short communications section. It provides the readers with interesting information about research done in the energy sector in Ukraine.

Publishing book reviews has become a tradition for our journal. In the current issue, one can find two. Nicholas Maxwell analyses J. D. Trout's innovative approach to the problem of the conditions of the birth of the scientific method. Maxwell introduces the main argument of the book while adding his own critical analysis. There is no doubt that chance plays a role in science but whether it could play a decisive role concerning introducing the scientific method altogether is an 
interesting problem that deserves further study. The review of Kevin C. Elliott's book by Francecso Orsi is a professional piece with an interesting insight by the author.

Once again, I am glad to welcome a new member to the Editorial Board of our journal. Professor Marcos Cueto is a well-known Latin American scholar who serves as President Elect of the Division of History of Science and Technology of the International Union of History and Philosophy of Science and Technology. Peruvian by birth, he was educated in the United States. Currently, Marcos Cueto works at the Casa de Osvaldo Cruz, a centre for the History of Science in Rio de Janeiro.

Unfortunately, life does not provide us only with positive events. With a deepest sadness in our soul, we must inform our readers that Tapio Markkanen, a good colleague from Finland and an exciting author of our journal, passed away in August this year. Tapio's research into the astronomy of the Moomin Valley tales by Tove Jansson is among the most widely read and cited pieces that our journal has ever included. We will miss Tapio and thank him for his great contribution to the journal and beyond.

My wish, however, is not to end on a sad note but rather emphasise the positive side-our achievements. A new interesting issue of our journal has become available. Let us enjoy reading it!

Peeter Mü̈rsepp

Editor-in-Chief 